\title{
Coupling of ingestion and defecation as a function of diet in the calanoid copepod Acartia tonsa
}

\author{
Sengul Besiktepe*, Hans G. Dam** \\ Department of Marine Sciences, University of Connecticut, Groton, Connecticut 06340-6048, USA
}

\begin{abstract}
The relationship between the rates of ingestion and defecation of the calanoid copepod Acartia tonsa was examined in laboratory experiments with different diets: the diatom Thalassiosira weissflogii, the autotrophic dinoflagellate Prorocentrum minimum, the heterotrophic dinoflagellate Oxyrrhis sp., the flagellate Dunaliella tertiolecta, and the bacterivorous scuticociliate Uronema sp. Experiments were run typically using between 6 and 8 concentrations ranging from 10 to $1150 \mu \mathrm{g} \mathrm{C}^{-1}$. Both diet and food concentration had significant effects on ingestion rate, pellet production rates and pellet volume. Ingestion and pellet production rates increased curvilinearly with food concentration. Copepods achieved the highest pellet production rates, the largest pellets and the shortest estimated gut passage times with the diatom diet. For all diets, gut passage time decreased with food concentration in the range 0 to ca. $250 \mu \mathrm{g} \mathrm{C}^{-1}$, but little thereafter. In addition, for all diets, but most obviously in the case of the diatom, pellet volume increased curvilinearly with food concentration. Maximum pellet volume was achieved at food concentrations ranging from 50 to $150 \mu \mathrm{g} \mathrm{C}^{-1}$. The defecation and ingestion rates were best correlated when the copepods fed on the diatom and the autotrophic dinoflagellate. Likewise, a decrease in estimated assimilation efficiency with increasing food concentration was apparent only for these 2 diets. This latter pattern is primarily due to an increase in pellet production rate, instead of pellet volume, relative to ingestion rate at the high food concentrations. We conclude that a diatom diet is the most likely one to result in attributes that enhance zooplankton-mediated export flux: high fecal pellet production rates, large pellet size and relatively low assimilation efficiency.
\end{abstract}

KEY WORDS: Carbon flux · Zooplankton · Copepod · Ingestion · Fecal pellet · Digestion · Assimilation efficiency · Omnivory

\section{INTRODUCTION}

Zooplankton play a key role in the efficiency of the biological pump (the flux of biologically produced organic carbon from the euphotic zone to deep waters) through modification of the composition and size spectrum of the particulate matter in the water column. This is in turn achieved by selective ingestion and subsequent processing of food resources (Fowler \& Knauer

\footnotetext{
*Present address: Institute of Marine Sciences, Middle East Technical University, PO Box 28, Erdemli, Icel 33731, Turkey

${ }^{* *}$ Corresponding author. E-mail: hans.dam@uconn.edu
}

1986, Small et al. 1989, Altabet \& Small 1990). Of particular importance to the gravitational component of the biological pump is the production of large, rapidly sinking fecal pellets (Fowler \& Knauer 1986, Noji 1991) - a process which is ultimately constrained by the zooplankter ingestion rate. In turn, food type affects ingestion rate (Vanderploeg 1990) as well as the size and density, and hence the sinking velocity of fecal pellets (Bienfang 1980, Dagg \& Walser 1986, Voss 1991, Urban et al. 1992, Feinberg \& Dam 1998).

The relevance of the relationship between ingestion $(I)$ and defecation $(E)$ is not confined to biogeochemical processes. For instance, other factors being equal, it would be advantageous to an organism to maximize its

(C) Inter-Research $2002 \cdot$ www.int-res.com 
assimilation efficiency $(1-E / I)$. In addition, if the relationship between defecation and ingestion is well established, defecation rate may be used to derive ingestion rate (e.g. Reeve \& Walter 1977, Ayukai \& Nishizawa 1986, Båmstedt et al. 1999). Finally, since ingestion depends on food concentration and type (Vanderploeg 1990), the coupling of ingestion and defecation helps one understand the relationship between defecation and food concentration and type.

Some previous studies have established a positive linear relation between the rate of fecal pellet production and food ingestion rate (Corner et al. 1972, Gamble 1978, Paffenhöfer \& Knowles 1979, Ayukai \& Nishizawa 1986, Tsuda \& Nemoto 1990). However, the slope of this relationship may vary with diet (Båmstedt et al. 1999). Less is known about the relationship between food ingestion rate and fecal pellet size. For instance, when the copepod Calanus finmarchicus feeds on the cryptophyte Rhodomonas baltica, pellet volume is independent of food ingestion (Båmstedt et al. 1999). However, since ingestion rate is related to food concentration and size (Vanderploeg 1990), and pellet size depends on food concentration (Dagg \& Walser 1986, Tsuda \& Nemoto 1990, Butler \& Dam 1994) and type (Bienfang 1980, Feinberg \& Dam 1998), there may be a relationship between pellet size and ingestion rate. Furthermore, Dagg \& Walser (1986) hypothesized that if the ingested material is processed continuously by the digestive system, then pellet size could be a function of the ingestion rate. On the other hand, if the gut is first filled and the food is subsequently digested, then pellet size could be independent of ingestion.

This paper is an extension of previous work (Butler \& Dam 1994, Feinberg \& Dam 1998) that seeks to systematically understand the factors that regulate the production rates and characteristics of copepod fecal pellets. In this study, we examine the functional responses (both ingestion and defecation) of the copepod Acartia tonsa as a function of 5 diets. The diets represent several planktonic groups, and also cover motile and non-motile preys. We then explore the coupling between ingestion rate, fecal pellet production rate and pellet size. Finally, we discuss our findings in the context of digestive processes and the implications for the downward flux of material in the ocean.

\section{MATERIALS AND METHODS}

Food and copepod cultures. All food and copepod cultures were grown in a walk-in chamber at $20 \pm 1^{\circ} \mathrm{C}$. The diatom Thalassiosira weissflogii was maintained in exponential growth in f/2 medium (Guillard 1975). The photosynthetic flagellate Dunaliella tertiolecta and the photosynthetic dinoflagellate Prorocentrum minimum were kept in exponential growth in f/2 medium without silica (Guillard 1975). The bacterivorous scuticociliate Uronema sp. was grown in a medium of $0.2 \mu \mathrm{m}$ filtered seawater with yeast extract ( 0.01 to $0.02 \%$ by volume) to sustain the bacteria upon which the ciliate fed (Feinberg \& Dam 1998). All of these food cultures were kept in a $12 \mathrm{~h}$ light: $12 \mathrm{~h}$ dark cycle $\left(\sim 100 \mu \mathrm{E} \mathrm{m} \mathrm{m}^{-2} \mathrm{~s}^{-1}\right)$. The heterotrophic dinoflagellate Oxyrrhis sp. was grown in f/50 medium with Isochrysis galbana as food. However, the culture was kept in the dark to prevent growth of I. galbana.

The calanoid copepod Acartia tonsa was continuously cultured in the laboratory in $15 \mathrm{l}$ plastic buckets bubbled with air. Cohorts of $A$. tonsa were grown from eggs of females collected from Long Island Sound, USA, and kept on a mixture of Isochrysis galbana, Thalassiosira weissflogii, Rhodomonas lens, Dunaliella tertiolecta and Tetraselmis impellucida, at a concentration of approximately $500 \mu \mathrm{gC} \mathrm{l}^{-1}$. The copepod culture medium was entirely replaced 3 times a wk.

Acclimation and incubation of copepods. Active adult females with intact appendages were selected from Acartia tonsa cultures and acclimated to the experimental food concentrations in 11 bottles for $48 \mathrm{~h}$ (Table 1). Cell numbers were measured using an Elzone 280 particle counter (Particle Data, USA). The initial volume and carbon content of the copepod food were measured as described in Feinberg \& Dam (1998). To measure cell carbon concentration, samples for CHN analysis were filtered onto combusted (at 450 to $500^{\circ} \mathrm{C}$ ) GF/D filters with $2.7 \mu \mathrm{m}$ pore size to minimize particulate carbon contribution by bacteria in the culture. The filters were dried at 55 to $60^{\circ} \mathrm{C}$ within aluminum foil capsules for approximately $36 \mathrm{~h}$, and processed using a Carlo Erba EA 1108 CHN analyzer (Fisons Instruments, Italy). Blank samples were prepared with culture medium using the same volume as the cell culture samples.

Experiments were run typically using between 6 and 8 concentrations ranging from 10 to $1150 \mu \mathrm{g} \mathrm{C} \mathrm{l}^{-1}$. We chose the lower food concentration based on the feeding threshold (assuming a $\mathrm{C}$ :chl a ratio of 50) of about 7 to $18 \mu \mathrm{g} \mathrm{C} \mathrm{l}^{-1}$ as observed by Reeve \& Walter (1977) for Acartia tonsa; the upper level of food concentration was determined by increasing food concentration to levels at which ingestion rate achieved steady state. We used 6 to 10 replicates of $144 \mathrm{ml}$ bottles each containing a single adult female for each experimental diet and concentration. The use of single females per bottle and the volume of the experimental containers were intended to minimize artifacts of bottle enclosures on ingestion rates and coprophagy, as well as to allow reliable measurements of ingestion rates. For instance, while larger experimental volumes would most likely result in less chance of coprophagy, we 
found in preliminary experiments with larger volumes $(260 \mathrm{ml})$ that we were unable to measure reliably ingestion rates at the lower food concentrations. Triplicate controls consisted of similar bottles without copepods. Bottles were placed on a rotating plankton wheel and after $24 \mathrm{~h}$ the contents of each bottle were gently sieved through a $20 \mu \mathrm{m}$ Nytex mesh to retain the females and the fecal pellets, whose width ranged from 29 to $57 \mu \mathrm{m}$. The filtrate was used for cell counts. Whether the female in each bottle was alive and active was recorded, then fecal pellets and the female were rinsed with $0.2 \mu \mathrm{m}$ filtered seawater and preserved in $5 \%$ formaldehyde. Prosome length and maximum width of females were measured using a dissecting microscope. The dry weight of females was calculated from the length-weight relationship given by Kiørboe et al. (1985) and their carbon content was calculated as $40 \%$ of their dry weight (Parsons et al. 1984). Bottles with dead copepods and with no measurable ingestion were not used in the analysis ( $7 \%$ of the cases). Cell concentrations at the start and end of the experiments were determined with the Elzone particle counter. The ingestion and clearance rates of food in each replicate were calculated according to the equations of Kiørboe et al. (1982). Whole pellets and pellet fragments were counted under a dissecting microscope and daily pellet production rates determined. To account for break up of pellets, pellet fragments were classified as either 1/2 or $1 / 3$ of a pellet, the total number of each type of fragment divided by 2 or 3 , as appropriate, and then added to the whole number of pellets. The length and width of intact pellets were measured at $50 \times$ magnification using a dissecting microscope. The volume of pellets was estimated assuming a cylindrical shape.

Gut passage time. The gut evacuation rate constant, GERC $\left(t^{-1}\right)$ as a function of food concentration for each diet was estimated as:

$$
\mathrm{GERC}=F / P
$$

where $F=$ pellet production rate (pellet ind.$^{-1} t^{-1}$ ) and $P=$ instantaneous number of pellets in the gut per individual. We never observed more than 2 pellets in the gut and rarely more than 1 pellet, which is similar to the observations of Kleppel et al. (1988). Hence, we assumed $P=1$ pellet ind. ${ }^{-1}$. Gut passage time, GPT $(t)$, was estimated as 1/GERC.

Assimilation efficiency. Assimilation efficiency (AE) $=(1-E / I) \times 100$, where $E$ and $I$ are the defecation and ingestion rates, respectively. From this definition, AE is derived from knowledge of 3 parameters measured in this study-ingestion rate, pellet production rate and pellet volume:

$$
\mathrm{AE}=[1-((F \times V \times D \times C W \times D W) / I)] \times 100
$$

in which $F$ is the defecation rate (number of fecal pellets copepod $\left.{ }^{-1} \mathrm{~d}^{-1}\right), V$ is volume of fecal pellets $\left(\mu \mathrm{m}^{3}\right.$ pellet $^{-1}$ ), $D$ is density (specific gravity) of fecal pellets $\left(\mu \mathrm{g} \mathrm{m}^{-3}\right), C W$ is carbon concentration in fecal pellets (\% of dry weight), DW is the dry weight (\% of wet weight) and $I$ is the ingestion rate $\left(\mu \mathrm{gC}\right.$ copepod $\left.{ }^{-1} \mathrm{~d}^{-1}\right)$. Values of $D$ used were the mean pellet densities of each diet measured by Feinberg \& Dam (1998). Since the densities of Prorocentrum minimum and Dunaliella tertiolecta were not measured in that study, we used those of Oxyrrhis marina (a dinoflagellate) and Tetraselmis sp. (a flagellate), respectively. Although in some cases pellet density varies with food concentration within a food (Feinberg \& Dam 1988), this is a small effect $(<5 \%$ change), which is ignored here. $D W$ was assumed to be $30 \%$ of the wet weight of the pellet $(V \times D)$ and $C W$ was assumed to be $25 \%$ of $D W$ (Morales 1987).

Statistical analysis. Statistical comparisons of the effects of food concentrations and type on ingestion,

Table 1. Summary of diets and concentrations used in experiments. ESD = equivalent spherical diameter. Values in parentheses are standard deviations of triplicate replicates. NMFS = National Marine Fisheries Service; CT: Connecticut, USA; LIS = Long

\begin{tabular}{|c|c|c|c|c|c|}
\hline Functional group & Species & $\begin{array}{l}\mathrm{ESD} \\
(\mu \mathrm{m})\end{array}$ & Strain origin & $\begin{array}{l}\text { Cell carbon } \\
\left(\mu \mathrm{gC} \mu \mathrm{m}^{-3}\right)\end{array}$ & $\begin{array}{l}\text { Experimental concentration } \\
\left(\mu \mathrm{C}^{-1}\right)\end{array}$ \\
\hline Diatom & $\begin{array}{l}\text { Thalassiosira } \\
\text { weissflogii }\end{array}$ & 10.2 & $\begin{array}{l}\text { NMFS collection } \\
\text { (Milford, CT) }\end{array}$ & $\begin{array}{l}5.8 \times 10^{-8} \\
\left(4.7 \times 10^{-9}\right)\end{array}$ & $11,20,28,50,61,118,238$ \\
\hline Flagellate & $\begin{array}{l}\text { Dunaliella } \\
\text { tertiolecta }\end{array}$ & 7.3 & $\begin{array}{l}\text { NMFS collection } \\
\text { (Milford, CT) }\end{array}$ & $\begin{array}{l}1.7 \times 10^{-7} \\
\left(1.2 \times 10^{-8}\right)\end{array}$ & $\begin{array}{l}45,86,126,135,250 \\
358,767,1132\end{array}$ \\
\hline $\begin{array}{l}\text { Autotrophic } \\
\text { dinoflagellate }\end{array}$ & $\begin{array}{l}\text { Prorocentrum } \\
\text { minimum }\end{array}$ & 12 & $\begin{array}{l}\text { NMFS collection } \\
\text { (Milford, CT) }\end{array}$ & $\begin{array}{l}2.8 \times 10^{-7} \\
\left(1.1 \times 10^{-8}\right)\end{array}$ & $34,89,173,268,537,771$ \\
\hline $\begin{array}{l}\text { Heterotrophic } \\
\text { dinoflagellate }\end{array}$ & Oxyrrhis sp. & 13.9 & Isolated from LIS & $\begin{array}{l}6.6 \times 10^{-8} \\
\left(1.1 \times 10^{-8}\right)\end{array}$ & $25,52,89,99,187,264$ \\
\hline Scuticociliate & Uronema sp. & 7.9 & $\begin{array}{l}\text { D. A. Caron (WHOI) } \\
\text { BBcil strain }\end{array}$ & $\begin{array}{l}1.1 \times 10^{-7} \\
\left(2.4 \times 10^{-8}\right)\end{array}$ & $18,35,63,121,272,435,723$ \\
\hline
\end{tabular}
Island Sound, USA; WHOI = Woods Hole Oceanographic Institution (Woods Hole, MA, USA) 

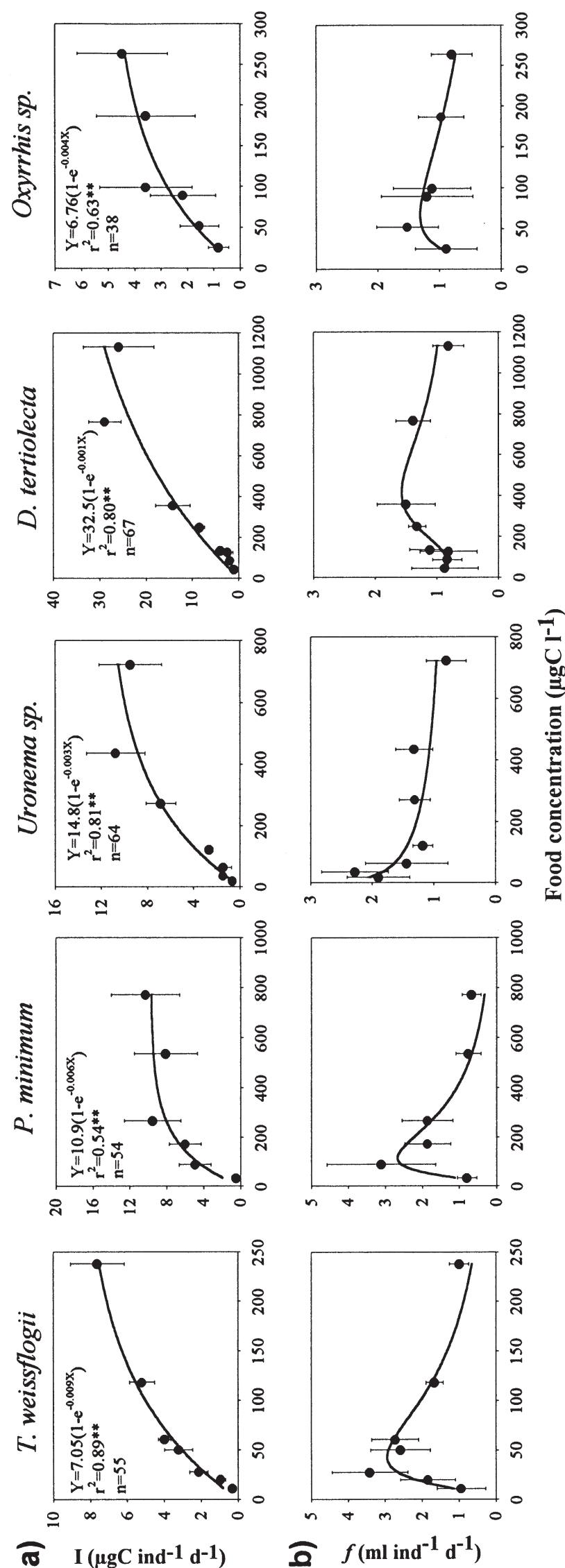

fecal pellet production, pellet volume and total pellet volume were done with 2-level nested ANOVA (Sokal \& Rohlf 1981). Linear and curvilinear (Ivlev) regressions were derived with SigmaPlot $^{\circledR}$ for Windows (V. 4.00). The Ivlev model employed was: $\mathrm{Y}=a\left(1-\mathrm{e}^{-b \mathrm{X}}\right)$, where $a$ is the asymptotic maximum value of $\mathrm{Y}$ (the dependent variable), and $b$ represents the rate of increase of $\mathrm{Y}$ with respect to $\mathrm{X}$ (the independent variable). Analysis of covariance (ANCOVA) was employed for comparisons of slopes of linear regressions.

\section{RESULTS \\ Ingestion and clearance rates}

To ease comparison among diets, we shall refer to them by their functional group (Table 1). The functional response of ingestion for all diets was fitted well by the Ivlev equation (Fig. 1a). The coefficients of determination ranged from 0.54 (the autotrophic dinoflagellate) to 0.89 (the diatom) (Fig. 1a). The functional response of ingestion changed significantly with diets $(\mathrm{p}<$ 0.025, 2-level nested ANOVA). Maximum ingestion rate ranged between 4.5 and $28.9 \mu \mathrm{gC}$ ind. ${ }^{-1} \mathrm{~d}^{-1}$ depending on the diet. Acartia tonsa feeding on the flagellate had the highest maximum ingestion rate, estimated as $28.9 \mu \mathrm{gC}$ ind.$^{-1} \mathrm{~d}^{-1}$ as compared to $10.7,10.0,7.5$ and $4.5 \mu \mathrm{gC}$ ind. ${ }^{-1} \mathrm{~d}^{-1}$ on the scuticociliate, the autotrophic dinoflagellate, the diatom and the heterotrophic dinoflagellate, respectively. With a typical body weight of $4.0 \mu \mathrm{g} \mathrm{C}$, maximal daily ingestion of $A$. tonsa ranged from the equivalent of $92 \%$ (the heterotrophic dinoflagellate) to $610 \%$ (the flagellate) of body carbon.

Clearance rate typically first increased with food concentration to a maximum and then declined, except in the case of the scuticociliate. (Fig. 1b). Maximum clearance rate was achieved from around 28 to $358 \mu \mathrm{g} \mathrm{C}^{-1}$, depending on the diet-approximately $30 \mu \mathrm{gC}^{-1}$ for both the diatom and the scuticociliate, and 89 and $52 \mu \mathrm{g} \mathrm{C}$ $\mathrm{l}^{-1}$ for the autotrophic and heterotrophic dinoflagellates, respectively. Clearance peaked at $358 \mu \mathrm{g} \mathrm{C} \mathrm{l}^{-1}$ for the flagellate, but a subsequent decrease was not obvious (Fig. 1b). To estimate the optimum size of food particles, the maximum clearance for each food was plotted against the cell size (ESD) (Fig. 2). With the exception of the heterotrophic dinoflagellate, the maximum clearance rate increased with cell ESD. Acartia 


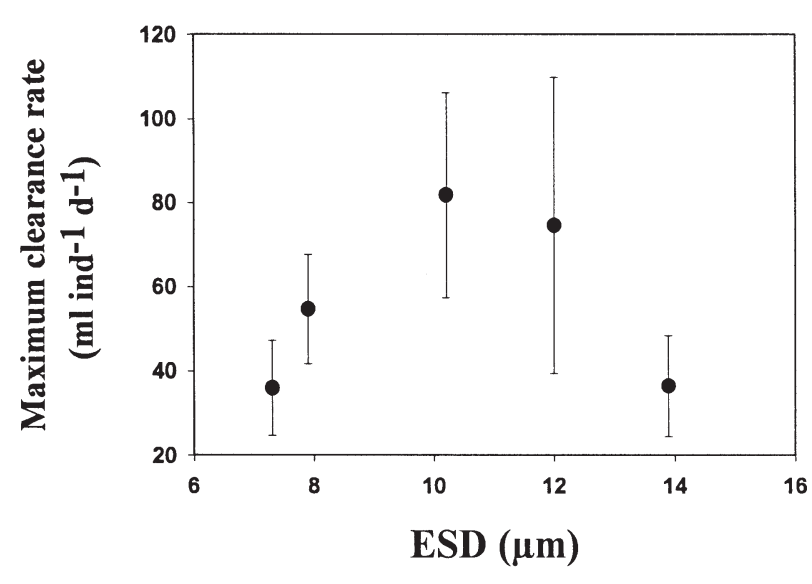

Fig. 2. Acartia tonsa. Maximum clearance rate (mean $\pm \mathrm{SD}$, $\mathrm{n}=6$ to 10) versus mean food particle equivalent spherical diameter (ESD). Each ESD corresponds to a different diet (see Table 1)

tonsa had the highest clearance with the autotrophic dinoflagellate and the diatom, at around $80 \mathrm{ml}$ ind. ${ }^{-1}$ $\mathrm{d}^{-1}$, whereas maximum clearance on the flagellate and the heterotrophic dinoflagellate was around $35 \mathrm{ml}$ ind. ${ }^{-1} \mathrm{~d}^{-1}$.

\section{Fecal pellet production}

Fecal pellet production by number and volume varied significantly with diet and with food concentration for each diet ( $p<0.01,2$-level nested ANOVA). Acartia tonsa tended to produce more pellets when fed the diatom and the autotrophic dinoflagellate (Fig. 3a). The maximum mean daily fecal pellet production was about 180 fecal pellets on the diatom diet. The volume of fecal pellet produced with the diatom was about twice as high as the other diets (Fig. 3b). Fecal pellet lengths were more variable than the widths. The coefficient of variation for pellet length ranged from $4 \%$ (the flagellate) to $20 \%$ (the diatom), and from $4 \%$ (the autotrophic dinoflagellate) to $11 \%$ (the diatom) for pellet width. Pellet production rate (number and total volume) increased curvilinearly with increasing food concentration in all diets (Fig. 3), with the Ivlev fit being, as indicated by the $\mathrm{r}^{2}$ values, best for the autotrophic dinoflagellate and worse for the heterotrophic dinoflagellate (Table 2). In contrast, a strong relationship $\left(\mathrm{r}^{2}=\right.$ 0.51) between pellet volume and food concentration was apparent only in the case of the diatom diet. Regardless of diet, mean pellet volume appeared to reach a maximum at relatively low food concentrations (50 to $150 \mu \mathrm{g} \mathrm{C}^{-1}$ ).

\section{Ingestion-defecation relationship}

The relationships between fecal pellet production rate (number and volume) and total fecal pellet volume versus ingestion of Acartia tonsa are presented in Fig. 4. Because the independent variable (ingestion) was not experimentally controlled, all pairs of observations are plotted. Where applicable, the summary statistics for Ivlev and linear fits for the relations mentioned above are presented in Table 3. In all cases, the

Table 2. Summary of Ivlev models fitted to the data on relationship between food concentration (Conc.) and daily fecal pellet production (FPP), pellet volume (Fec. vol.) and total pellet volume production (Tot. vol.) of Acartia tonsa females. The Ivlev model employed was: $\mathrm{Y}=a\left(1-\mathrm{e}^{-b \mathrm{X}}\right)$, where $a$ is the asymptotic maximum value of $\mathrm{Y}$ (FPP or Fec. vol or Tot. vol.), and $b$ represents the rate of increase of $\mathrm{Y}$ with respect to $\mathrm{X}$ (food concentration). Units of $\mathrm{Y}$ and $\mathrm{X}$ are given in Fig. $3 . \mathrm{n}=$ sample size, $\mathrm{r}^{2}=$ coefficient of determination, and $\mathrm{p}=$ probability that $b$ is not different from zero. Full species names given in Table 1

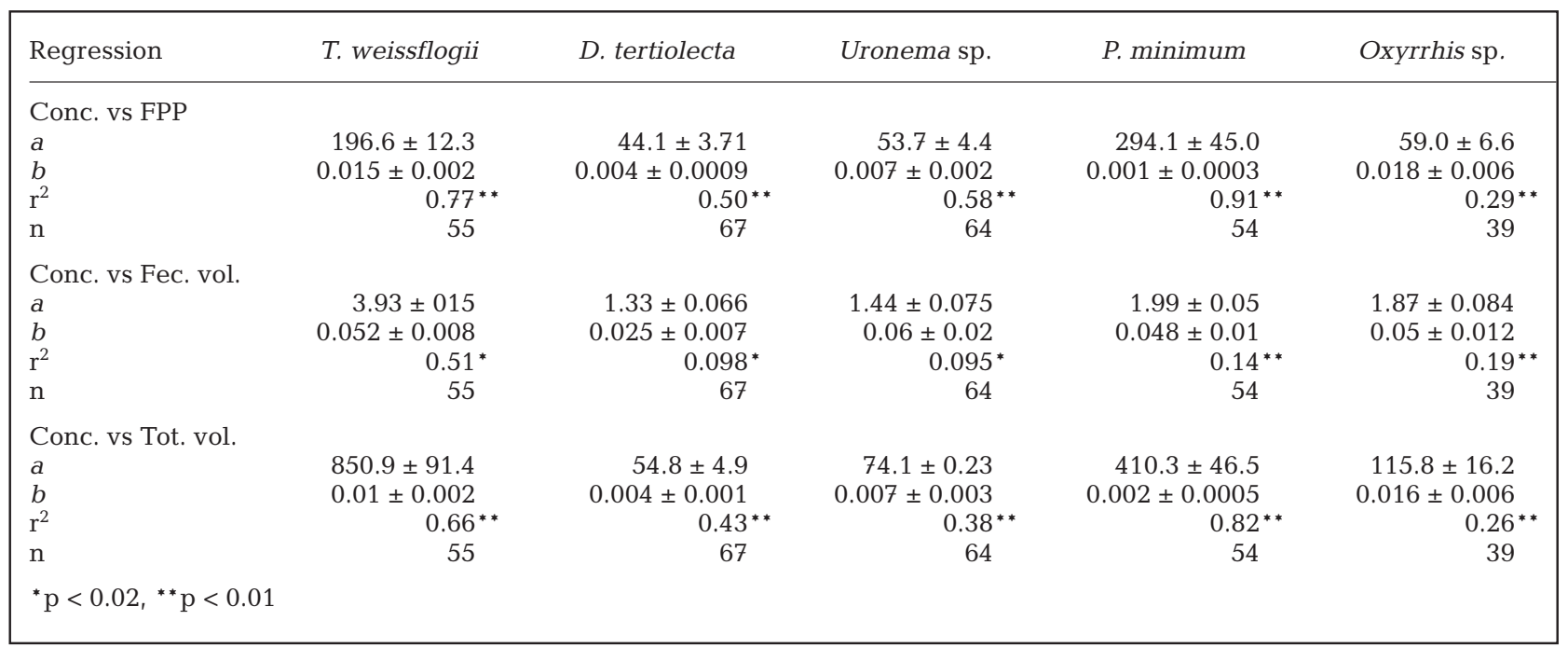



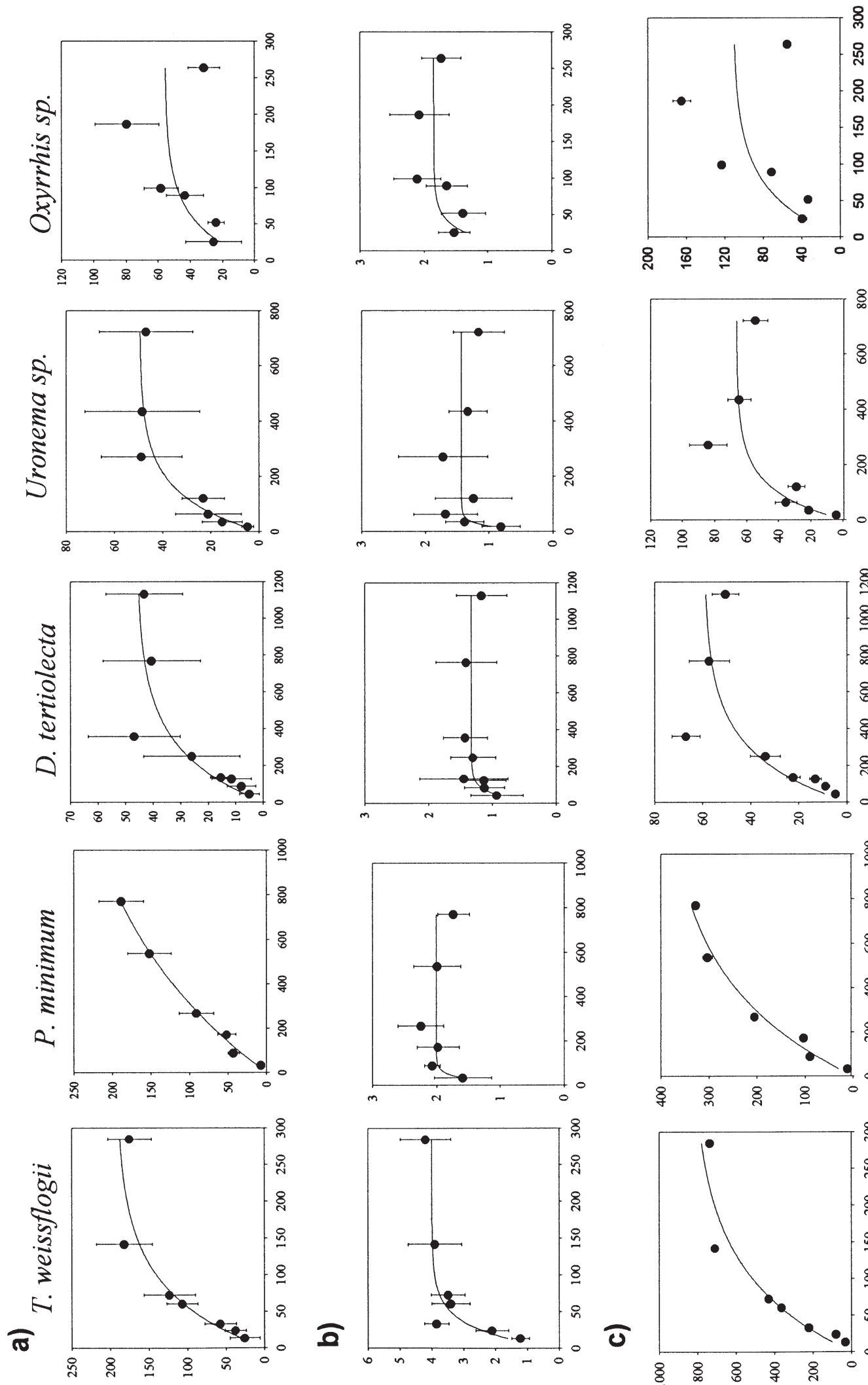

FPP (No. ind $\mathbf{d}^{-1} \mathrm{~d}^{-1}$ )

Pellet volume $\left(\mu \mathrm{m}^{3} \times 10^{5}\right.$ pellet $\left.^{-1}\right)$
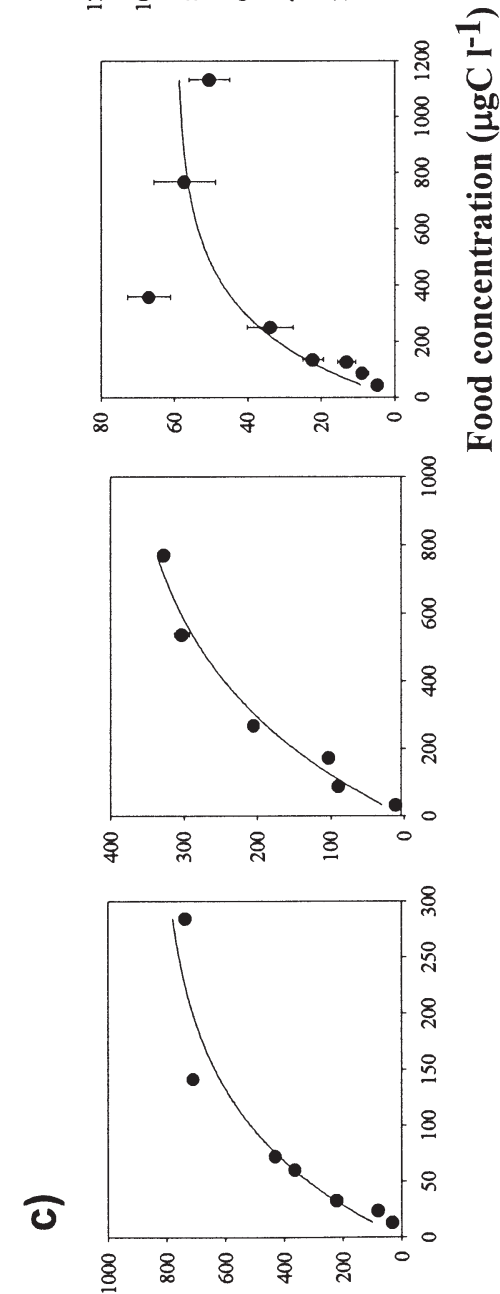

Total pellet volume

$\left(\mu \mathrm{m}^{3} \times 10^{5}\right.$ ind $\left.^{-1} \mathrm{~d}^{-1}\right)$

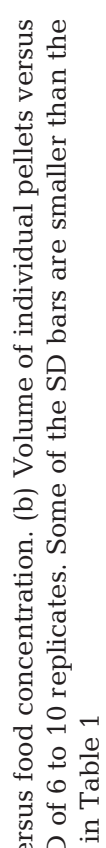

I $\quad$ 品

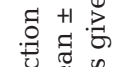

贾

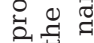

包

2.

웡

$\gtrsim \vec{y}$

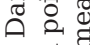

ฮ뮴

வ்

영

资营

$\triangle$ वृँ

w

$\bar{\sigma}:$

(ृ.

传?

:

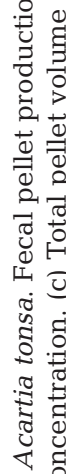

लं

홍ํㅇ 

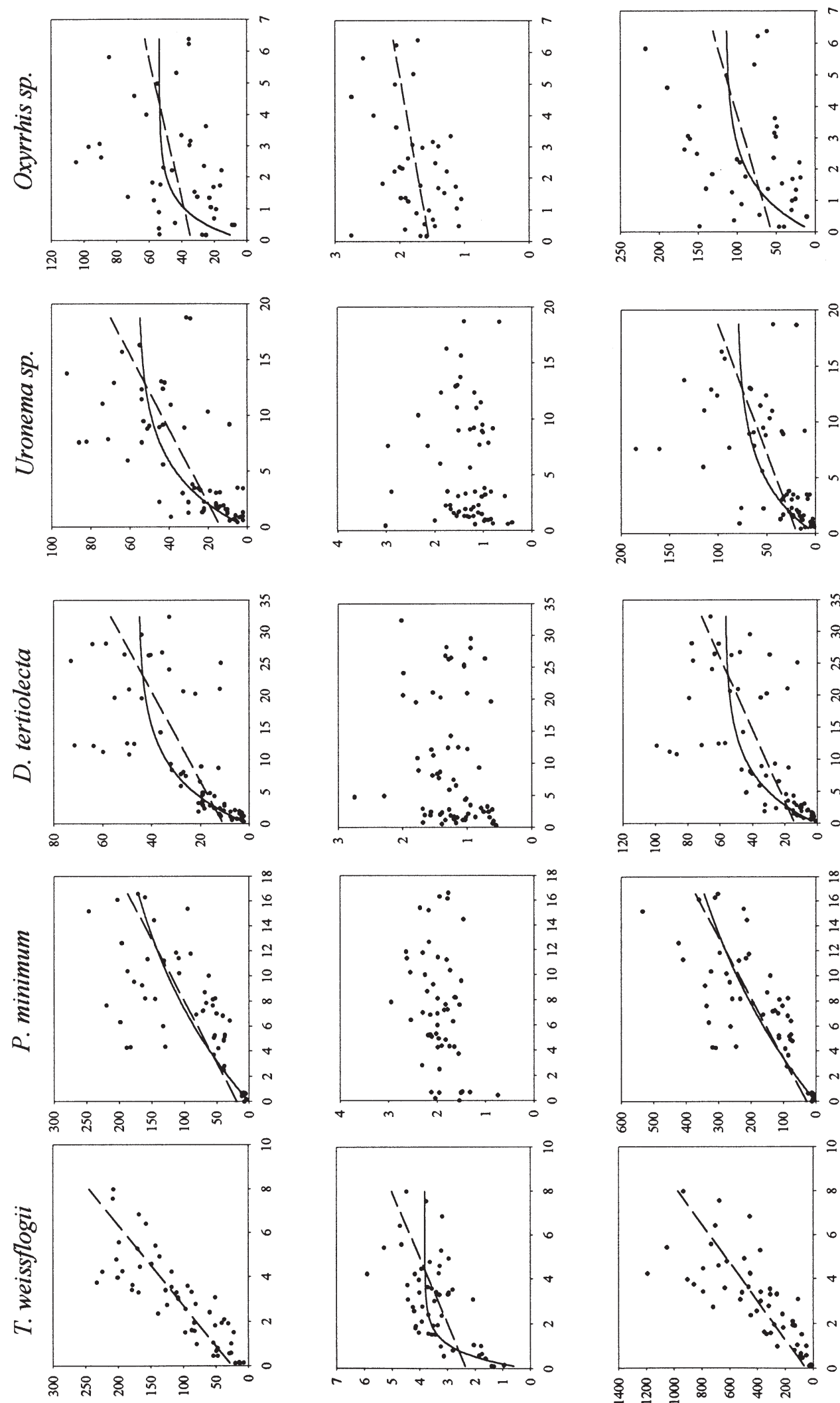

FPP (No. ind $\mathrm{d}^{-1} \mathrm{~d}^{-1}$ )

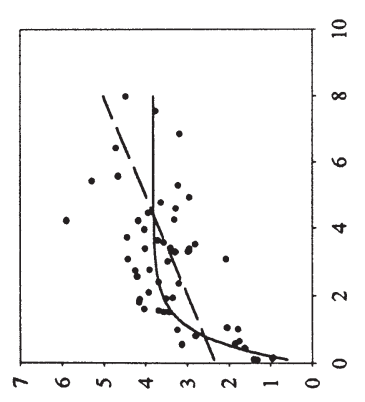

Pellet volume $\left(\mu \mathrm{m}^{3} \times 10^{5}\right.$ pellet $\left.^{-1}\right)$

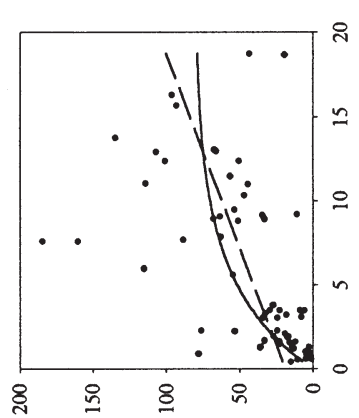

To

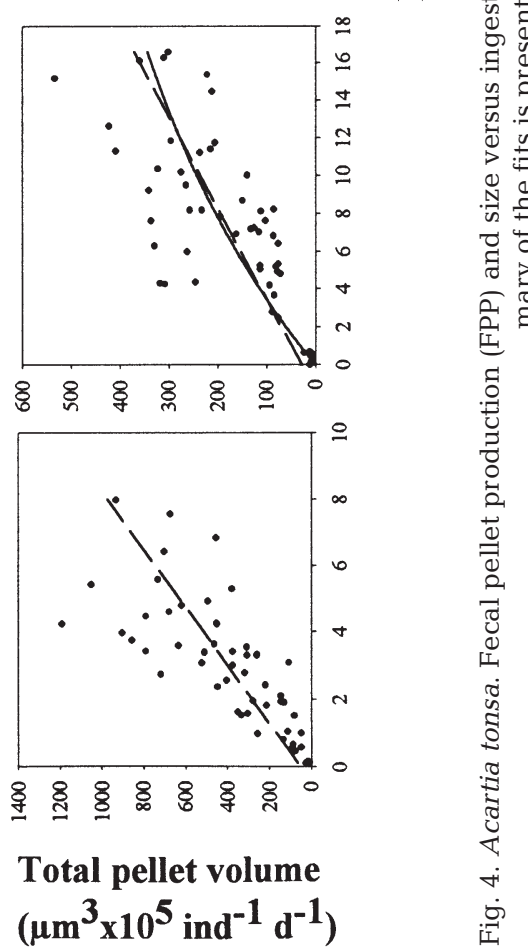




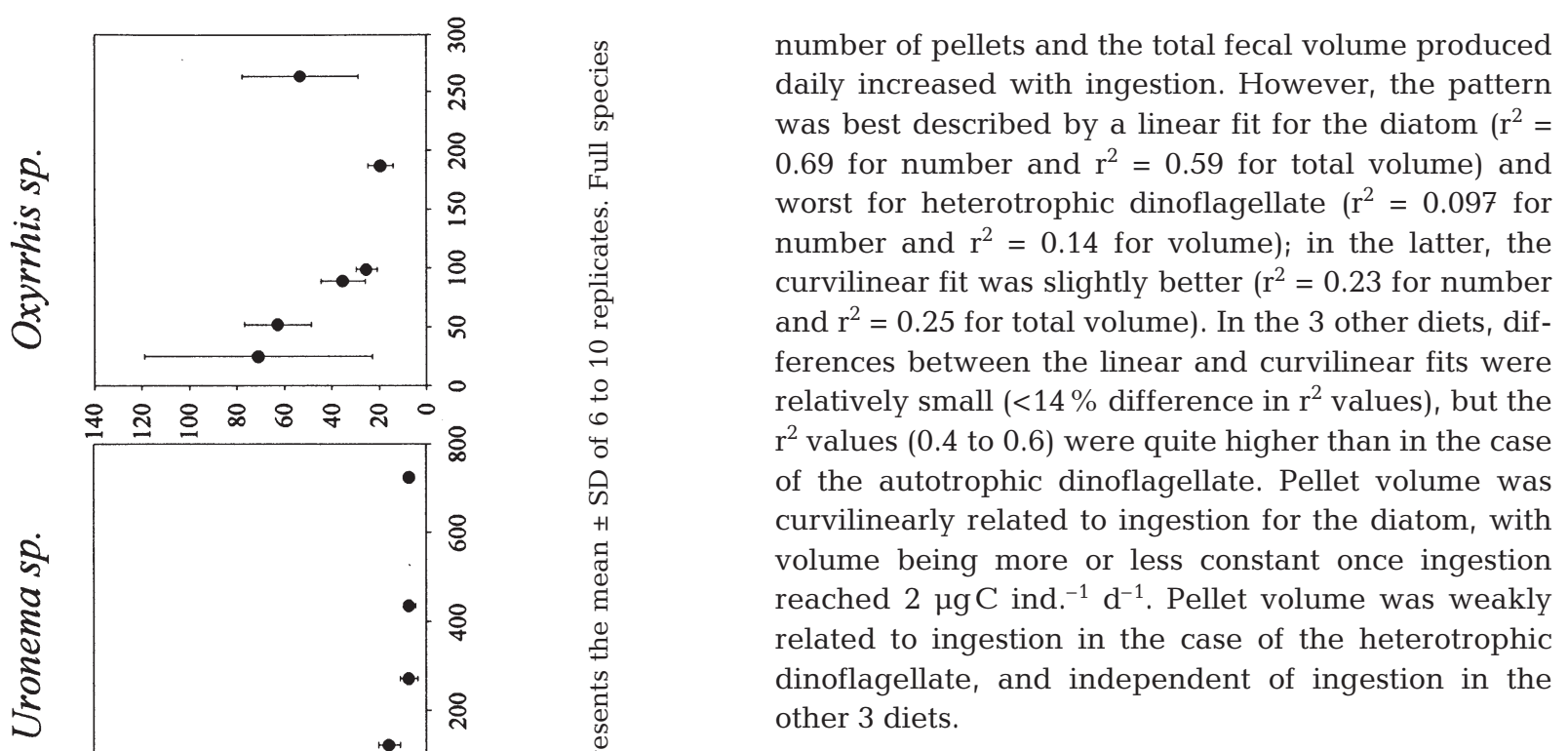

\section{Gut passage time}

The relationship between gut passage time (GPT) and food concentration is shown in Fig. 5. GPT declined rapidly with food concentration for all diets, at the lower food concentrations ( 0 to $\sim 250 \mu \mathrm{g} \mathrm{C} \mathrm{l}^{-1}$ ). GPT varied little with food concentration once concentrations were beyond $\sim 250 \mu \mathrm{g} \mathrm{Cl}^{-1}$. GPT ranged from a minimum of about $10 \mathrm{~min}$ to a maximum of about $300 \mathrm{~min}$. We derived regressions of GPT versus food concentration assuming an exponential decay model (Ln $Y$ versus $X$ ). To compare the slopes of these rela-

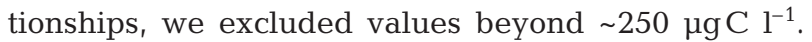
The rank of the slopes, which varied by more than an order of magnitude among foods, was as follows: diatom $(-0.003)>$ flagellate $(-0.0094)=$ autotrophic dinoflagellate $(-0.0091)=$ scuticociliate $(-0.0076)>$ heterotrophic dinoflagellate $(-0.0028)$ (ANCOVA, $\mathrm{p}<$ 0.05).

\section{Assimilation efficiency}

The relationship between assimilation efficiency (AE) and food concentration varied with diet (Fig. 6). AE were lowest for the diatom ( 15 to $50 \%)$ and highest for the flagellate $(>90 \%)$. AE were also relatively high $(>80 \%)$ with the ciliate diet. There appeared to be a decrease in assimilation efficiency with food concentration with the diatom, and both the autotrophic and heterotrophic dinoflagellate diet. However, the pattern was significant only in the case of the diatom $\left(Y=0.41 \mathrm{e}^{-0.042 \mathrm{X}}, \mathrm{r}^{2}=0.16, \mathrm{n}=32, \mathrm{p}<0.01\right)$ and the autotrophic dinoflagellate diet $\left(Y=0.77 \mathrm{e}^{-0.005 X}, \mathrm{r}^{2}=\right.$ $0.26, \mathrm{n}=51, \mathrm{p}<0.01$ ). We did not attempt to examine 
Table 3. Summary of linear and Ivlev models fitted to the data on relationship between ingestion, Ing. $\left(\mu \mathrm{g} \mathrm{C}\right.$ ind..$\left.^{-1} \mathrm{~d}^{-1}\right)$, and daily fecal pellet production (FPP), pellet volume (Fec. vol.) and total pellet production (Tot. vol.) of Acartia tonsa females. In the Ivlev model X is Ing., and Y is FPP or Fec. Vol. or Tot. vol. Units of the dependent variables are given in Fig. 4. Other abbreviations of the Ivlev model as in Table 2. For the linear regression, $a=$ intercept and $b=$ slope. $\mathrm{ns}=$ not significant $(\mathrm{p}>0.05)$. Full species names given in Table 1

\begin{tabular}{|c|c|c|c|c|c|c|c|c|c|c|}
\hline \multirow[t]{2}{*}{ Regression } & \multicolumn{2}{|c|}{ T. weissflogii } & \multicolumn{2}{|c|}{ D. tertiolecta } & \multicolumn{2}{|c|}{ Uronema sp. } & \multicolumn{2}{|c|}{ P. minimum } & \multicolumn{2}{|c|}{ Oxyrrhis sp. } \\
\hline & Linear & Ivlev & Linear & Ivlev & Linear & Ivlev & Linear & Ivlev & Linear & Ivlev \\
\hline \multicolumn{11}{|l|}{ Ing. vs FPP } \\
\hline$a$ & 25.3 & ns & 10.498 & 45.3 & 13.55 & 55.76 & 18.5 & 247.2 & 34.1 & 53.67 \\
\hline$b$ & 0.85 & ns & 1.43 & 0.14 & 3.01 & 0.214 & 10.14 & 0.07 & 4.49 & 1.25 \\
\hline$r^{2}$ & $0.69^{* *}$ & ns & $0.50^{* *}$ & $0.62^{* *}$ & $0.43^{* *}$ & $0.54^{* *}$ & $0.46^{* *}$ & $0.48^{* *}$ & $0.097^{*}$ & $0.23^{* *}$ \\
\hline $\mathrm{n}$ & 55 & & 67 & 67 & 64 & 64 & 54 & 54 & 39 & 39 \\
\hline \multicolumn{11}{|c|}{ Ing. vs Fec. vol. } \\
\hline a & 2.31 & 3.8 & ns & ns & ns & ns & ns & ns & 1.54 & ns \\
\hline$b$ & 0.34 & 1.41 & ns & ns & ns & ns & ns & ns & 0.087 & ns \\
\hline$r^{2}$ & $0.38^{* *}$ & $0.64^{* *}$ & ns & ns & ns & ns & ns & ns & $0.12^{*}$ & ns \\
\hline $\mathrm{n}$ & 55 & 55 & & & & & & & 39 & \\
\hline \multicolumn{11}{|c|}{ Ing. vs Tot. vol. } \\
\hline$a$ & 48.66 & ns & 13.8 & 56.65 & 18.66 & 80.34 & 27.49 & 574.5 & 55.26 & 114.01 \\
\hline$b$ & 115.78 & ns & 1.78 & 0.15 & 4.33 & 0.21 & 20.69 & 0.055 & 11.85 & 0.74 \\
\hline $\mathrm{r}^{2}$ & $0.59^{* *}$ & ns & $0.44^{* *}$ & $0.56^{* *}$ & $0.30^{* *}$ & $0.37^{* *}$ & $0.54^{* *}$ & $0.56^{* *}$ & $0.14^{*}$ & $0.25^{* *}$ \\
\hline $\mathrm{n}$ & 55 & & 67 & 67 & 64 & 64 & 54 & 54 & 39 & 39 \\
\hline
\end{tabular}

the relationship of $\mathrm{AE}$ with ingestion rate (e.g. Gaudy 1974) because AE is partly based on ingestion rate (Eq. 1).

\section{DISCUSSION}

\section{Ingestion rate and food type}

The maximum ingestion rates, expressed as percentage of carbon body weight consumed daily, observed in this study are within the range observed for the genus Acartia, which can readily achieve rates equivalent to $100 \%$ of body carbon at high food concentrations (Durbin \& Durbin 1992), or higher. For instance, Paffenhoffer (1988) reported values of up to $360 \%$ of daily body weight for A. tonsa, and Deason (1980) reported up to $660 \%$ of body carbon for A. hudsonica.

The relationship between ingestion and food concentration in the present study showed, regardless of food type, the typical curvilinear pattern exhibited by many copepod species (Vanderploeg 1990). In addition, the 2-level ANOVA revealed the effect of food type on the functional response, as has been reported by others (Houde \& Roman 1987, Rothhaupt 1990). The effect of food type on the functional response was manifested in at least 2 ways. One is the relationship between the rate at which ingestion rate increases with food concentration versus food type, as evidenced by the slopes of Ivlev curvilinear fits in Fig. 1. The highest slopes corresponded to copepods feeding on the dia- tom and the autotrophic dinoflagellate. The other way is the relationship between maximum clearance rate and food size, with maxima also obtained when the copepods fed on these same 2 diets (Fig. 2). In the present study, the food ESD ranged from 7.3 (the flagellate) to $13.9 \mu \mathrm{m}$ (the heterotrophic dinoflagellate). The optimum food size (the size at which clearance is maximum) is a complex function of many variables, including the retention ability and the size of copepods (Berggreen et al. 1988, Støttrup \& Jensen 1990). For Calanus finmarchicus, the optimum size is $30 \mu \mathrm{m}$ (Gamble 1978), and around $17 \mu \mathrm{m}$ for Pseudocalanus elongatus (Koski et al. 1998). We observed the optimum food size for Acartia tonsa to be 10 to $12 \mu \mathrm{m}$, which is identical to the lower limit of optimum particle size reported by Berggreen et al. (1988), and Støttrop \& Jensen (1990) for A. tonsa.

Factors other than food size also influenced the functional response. The rates of ingestion of the heterotrophic dinoflagellate were much lower than those of the flagellate and the scuticociliate, despite the larger size of the former. The latter 2 foods are not optimal at supporting metabolism and growth of Acartia tonsa (Støttrup \& Jensen 1990, Thor et al. in press). Thus, the high ingestion rate for these 2 foods may have been necessary to achieve the copepod daily requirements of biochemical compounds for growth (Tang \& Dam 1999). Alternatively, sloppy feeding (incomplete ingestion of particles) may have occurred. Typically, sloppy feeding results in food particle fragmentation. However, if that was the case 


\section{T. weissflogii}

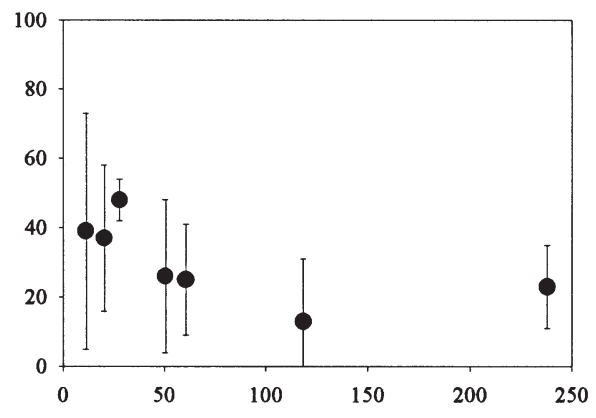

P. minimum

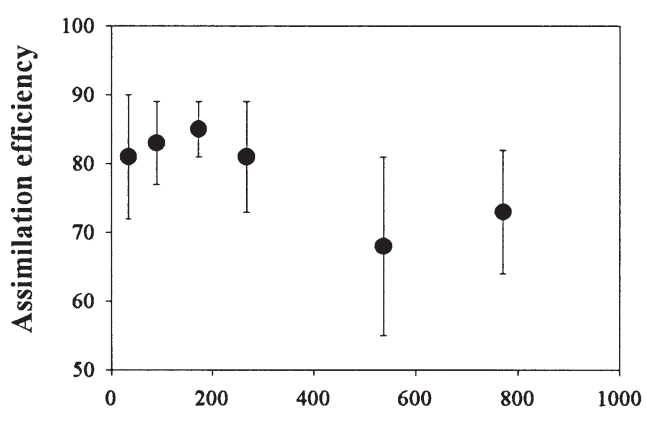

D. tertiolecta

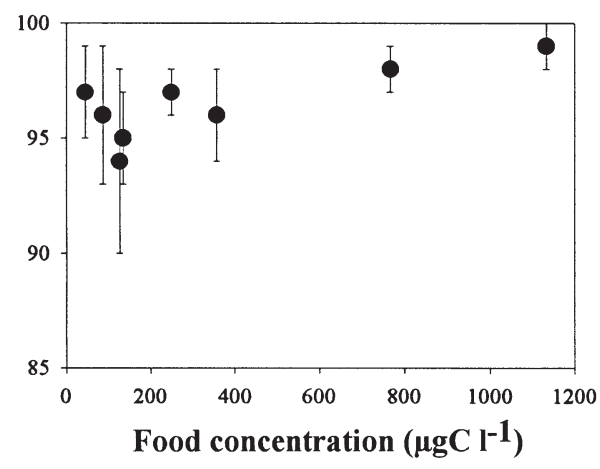

in our study, then the food fragments had to be below the size detection limit of $3 \mu \mathrm{m}$ of our particle counter because the particle size spectrum before and after incubation experiments with these 2 diets did not change significantly.

\section{Defecation rate, gut passage time and assimilation efficiency versus food type}

Previous studies of zooplankton fecal pellets indicate that different diets yield different pellet production rates and pellet characteristics (summarized in Feinberg \& Dam 1998). However, with few exceptions (e.g. Gaudy 1974, Griffin 2000) most studies have dealt with
Uronema sp.

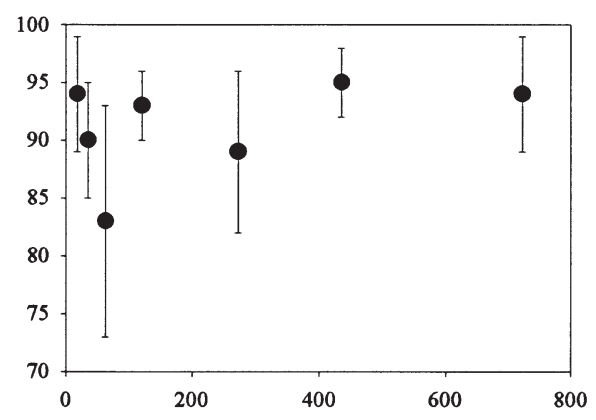

Oxyrrhis sp.

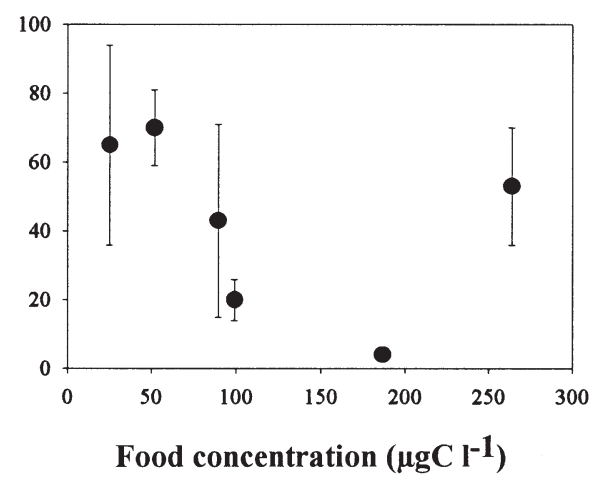

Fig. 6. Acartia tonsa. Estimated carbon assimilation efficiency versus food concentration as a function of diet. Each point represents the mean \pm SD of 6 to 10 replicates. Full species names given in Table 1

1 , or at best 2 diets. Hence, comparison of diet effects among studies is complicated by many other factors. In the present study, the fecal pellet production in terms of number and total volume changed significantly with diet and with food concentrations, and a curvilinear functional response curve was observed for the pellet production (Fig. 3). Pellet volume increased curvilinearly with food concentration. However, this relationship was strong only in the case of the diatom. This may simply reflect the fact that many more measurements were done at the low food concentration with this diet than with the rest. Clearly, for all diets pellet volume appears unrelated to food concentration when the latter exceeds $\sim 100 \mu \mathrm{g} \mathrm{Cl}^{-1}$. This is consistent with previous observations (Dagg \& Walser 1986, Tsuda \& 
Nemoto 1990, Butler \& Dam 1994, Båmstedt et al. 1999).

Estimates of gut passage time, which are related to the pellet production rate, showed rapid decrease with food concentration for all diets. A similar pattern has been observed in other studies using a diatom (Dagg \& Walser 1987), and natural seston (Tsuda \& Nemoto 1987) as food. Numerous studies have derived gut passage time from the empirical relationship between gut clearance rate and temperature of Dam \& Peterson (1988). However, since that relationship was derived under non-limiting food conditions, the results from the present study suggest that at very low food concentrations, gut passage time will be underestimated when derived from temperature alone.

Assimilation efficiencies in the present study are rough estimates because total recovery of the fecal matter produced may not have occurred. This would result in an overestimation of the assimilation efficiency. There are also possible unknown errors in the factors employed in Eq. (2) to convert wet and dry weight to carbon. For instance, Urban-Rich et al. (1998) found that the carbon to volume ratio of copepod pellets was independent of food type at a constant concentration, but increased with food concentration. We reasoned that the latter finding does not apply to Acartia tonsa since their pellet density does not increase significantly with food concentration (Feinberg \& Dam 1998). Moreover, the main purpose of estimating assimilation efficiencies in the present study was to reveal gross differences among diets. Conover (1978) reported a mean zooplankton assimilation efficiency of $70 \pm 30 \%$, which was based on several hundreds of measurements. However, there is some evidence that copepod assimilation efficiency decreases with food concentration (Gaudy 1974, Landry et al. 1984), and that it can be much lower (10 to $20 \%$ ) than the $70 \%$ mean at high food concentrations (Gaudy 1974). Assimilation efficiency decreased with food concentration when copepods fed on the diatom and the autotrophic dinoflagellate, but this was not clear for the other diets, particularly for the flagellate and the scuticociliate (Fig. 6). The results of the present study thus suggest that a decrease in assimilation efficiency with increasing food concentration is not always warranted, even in copepods acclimated to their food source. Assimilation efficiencies on the latter 2 diets were also quite high $(>90 \%)$, whereas those of the former diet were lower $(\sim 20$ to 85), particularly in the case of the diatom. These lower assimilation efficiencies may reflect a larger fraction of the organic carbon being associated with the structural components of the cells that are not easily digested (Reinfelder \& Fisher 1991, Cowie \& Hedges 1996).

\section{Potential bias due to pellet degradation and coprophagy}

Pellet degradation and coprophagy can lead to underestimation of fecal pellet production or pellet volume, which in turn would bias estimates of assimilation efficiency and the relationship between ingestion and defecation rate. Diet and food concentration influence fecal pellet degradation (Lee \& Fisher 1994, Hansen et al. 1996). Hansen et al. (1996) observed faster fecal pellet degradation rates for pellets produced on a ciliate diet than on a diatom diet. Hence, we tested the degradation of fecal pellets by using the scuticociliate, Uronema sp. Fecal pellets were incubated at 1 low $\left(30 \mu \mathrm{gC} \mathrm{l}^{-1}\right)$ and 1 high $\left(500 \mu \mathrm{g} \mathrm{C}^{-1}\right)$ concentration of Uronema sp. for $24 \mathrm{~h}$. Before and after the incubation, their length and width were measured using a dissecting microscope with $50 \times$ magnification. In contrast with the findings of Hansen et al. (1996), we did not observe any significant differences in fecal pellet length and width, before and after the experiments (Paired-samples $t$-test, $\mathrm{p}>0.05, \mathrm{n}=6$ ). A similar result to ours was obtained by Feinberg \& Dam (1998). Thus, we can be confident that the measured pellet production rates and the pellet sizes in this study were not unduly affected by degradation.

Fecal pellet repackaging (coprophagy) has been reported at low food concentrations (Paffenhöfer \& Knowles 1979, Green et al. 1992). We did a simple test to examine coprophagy with Uronema sp. as the food source at low food concentration $\left(30 \mu \mathrm{g} \mathrm{Cl}^{-1}\right)$. Uronema cells were labeled with yellow fluorescent dye (Dolan \& Coats 1991), and female Acartia tonsa were allowed to feed on these cells, and produced fluorescent (yellow) pellets (normally pellets produced on Uronema are white). Eight replicates (single female in $144 \mathrm{ml}$ bottles) incubations, each with $30 \mu \mathrm{g} \mathrm{Cl}^{-1}$ of unlabeled Uronema cells and 5 labeled pellets, were prepared. Two bottles were sacrificed at 2.5 and $3.5 \mathrm{~h}$, respectively. The other 4 bottles were sacrificed at $24 \mathrm{~h}$. Of the 40 fluorescent pellets, we observed 2 eaten by $A$. tonsa females (one in the gut at $t=2.5 \mathrm{~h}$, and another (half fluorescent, half white) at $t=3.5 \mathrm{~h}$ ). Hence, loss of pellets to cophrophagy was $5 \%$. Thus, cophropaghy in this study did not appear to result in gross underestimation of fecal pellet production.

\section{Ingestion-defecation relationship}

A main goal of this study was to be able to quantify the relationship between ingestion and fecal pellet production. Fecal pellet production in terms of number and total pellet volume was dependent on ingestion for all diets (see Table 3 ). Past studies have shown a posi- 
tive linear relationship between ingestion and fecal pellet production (Gaudy 1974, Gamble 1978, Ayukai \& Nishizawa 1986, Tsuda \& Nemoto 1990, Båmstedt et al. 1999). In this study, the relationship between ingestion and defecation in terms of number and total pellet volume was well described by linear fit for the diatom, but the curvilinear fit was slightly better for the other diets. Clearly, and in agreement with the results of Båmstedt et al. (1999) in their study with Calanus finmarchicus fed on the flagellate Rhodomonas baltica and the haptophyte Emiliania huxleyi, a single equation relating defecation and ingestion rate is not warranted. Consequently, food type should be considered when ingestion rate is estimated from defecation rate.

Fecal pellet volume appears to be independent of the ingestion rate, with the exception of the diatom and the heterotrophic dinoflagellate diet, albeit weakly for the latter (Table 3). The stronger relationship between pellet volume and ingestion for the diatom could be explained within the context of Dagg \& Walser's hypothesis (1986) outlined in the 'Introduction'. Thus, based on this hypothesis one would infer that digestion of the diatom would be a continuous process. However, this explanation would apply to relatively low food concentrations because of the apparent lack of relationship between pellet volume and food concentrations at high food concentrations. Acartia tonsa employs a continuous suspension feeding mode in the presence of nonmotile food items such as diatoms, and a raptorial feeding mode in the presence of motile food items such as flagellates and ciliates (Kiørboe et al. 1996). This latter feeding mode is more akin to the copepod having discrete meals, and there is some evidence that intermittent feeding occurs in nature for A. tonsa (Kleppel et al. 1988). In the context of Dagg \& Walser's (1986) hypothesis, then one would expect that pellet size of $A$. tonsa be related to ingestion in the case of non-motile food items, but not in the case of motile food items, which is consistent with the results of the present study.

Because the calculation of assimilation efficiency employed here involved the ingestion rate, statistical relationships between these 2 parameters are not warranted due to autocorrelations. However, we may gain some insights on the dynamics of gut filling and emptying and on what might control assimilation efficiency by simultaneously examining the response of defecation rate and ingestion rates to food concentration. Since $\mathrm{AE} \propto(1-P V / I)$, changes in assimilation efficiency depend on how rapidly pellet volume and pellet production rate increase with food concentration relative to ingestion rate. At low food concentrations, pellet volume increases with food concentration faster than pellet production rate (Table 2, Fig. 2a,b), and consequently assimilation efficiency is most sensitive to pellet volume. Once pellet volume reaches its maximum, assimilation efficiency depends on pellet production rate. Thus, the decrease in assimilation efficiency at high food concentrations with the diatom and autotrophic dinoflagellate diet reflects an uncoupling of ingestion and pellet production such that the latter increases faster than the former with food concentration.

\section{Implications for export flux}

Export production is the equivalent fraction of primary production (typically expressed in carbon currency) that sinks below the euphotic zone. Zooplankton contribute to export flux by means of active transport due to diel vertical migration (Longhurst \& Harrison 1988, Dam et al. 1995) and by their production of fast sinking pellets (Fowler \& Knauer 1986). The fecal pellet carbon flux at the base of the euphotic zone equals the product of pellet concentration and pellet sinking rate. The first term is represented by the fraction of total pellet carbon that reaches the base of the euphotic zone. Other factors (e.g. ingestion) being equal, zooplankton diets that result in low assimilation efficiency, high pellet production rates, high sinking rates and low pellet degradation rates will result in higher concentration of fecal pellet carbon reaching the base of the euphotic zone. In the present study, Acartia tonsa displayed the highest pellet production rates and the lowest assimilation efficiency with the diatom diet. Likewise, the highest ratio of sinking rate to degradation rate for fecal pellets of this copepod is likely to occur with the diatom diet (Feinberg \& Dam 1998). Thus, ingestion of diatoms is likely to result in a large fraction of the fecal carbon reaching the base of the euphotic zone. In addition, ingestion of diatoms by A. tonsa resulted in large-sized pellets with sinking rates only exceeded by those produced on a ciliate diet (Feinberg \& Dam 1998). However, the results from the present study suggest that higher assimilation efficiency and lower pellet production rates are achieved with the ciliate than with the diatom diet. Therefore, we conclude that of all the diets examined in this study, ingestion of diatoms by copepods is likely to result in enhanced export flux.

Acknowledgements. This study was supported by grant NSFOCE 9521907 (CAREER) awarded to H.G.D. We thank G. McManus, K.W. Tang and S. Colin for assistance in various aspects of the experiments in this study, and 3 anonymous reviewers for critically reading the manuscript.

\section{LITERATURE CITED}

Altabet MA, Small LF (1990) Nitrogen isotopic ratios in fecal pellets produced by marine zooplankton. Geochim Cosmochim Acta 54:155-163 
Ayukai T, Nishizawa S (1986) Defecation rate as a possible measure of ingestion rate of Calanus pacificus pacificus (Copepoda: Calanoida). Bull Plankton Soc Jpn 33:3-10

Båmstedt U, Nejstgaard JC, Solberg PT (1999) Utilisation of small-sized food algae by Calanus finmarchicus (Copepoda, Calanoida) and the significance of feeding history. Sarsia 84:19-38

Berggreen U, Hansen B, Kiørboe T (1988) Food size spectra, ingestion and growth of the copepod Acartia tonsa during development: implications for determination of copepod production. Mar Biol 99:341-352

Bienfang PK (1980) Herbivore diet affects fecal pellet settling. Can J Fish Aquat Sci 37:1352-1357

Butler M, Dam HG (1994) Production rates and characteristics of fecal pellets of the copepod Acartia tonsa under simulated phytoplankton bloom conditions: implications for vertical fluxes. Mar Ecol Prog Ser 114:81-91

Conover RC (1978) Transformation of organic matter. In: Kinne O (ed) Marine ecology, Vol 4. Wiley-Liss Inc, New York, p 221-499

Corner EDS, Head RN, Kilvington CC (1972) On the nutrition and metabolism of zooplankton VIII. The grazing of Biddulphia cells by Calanus helgolandicus. J Mar Biol Assoc UK 52:847-861

Cowie GL, Hedges JI (1996) Digestion and alteration of the biochemical constituents of a diatom (Thalassiosira weissflogii) ingested by a herbivorous zooplankton (Calanus pacificus). Limnol Oceanogr 41:581-594

Dagg MJ, Walser WE Jr (1986) The effects of food concentration on fecal pellet size in marine copepods. Limnol Oceanogr 31:1066-1071

Dagg MJ, Walser WE Jr (1987). Ingestion, gut passage, and egestion by the copepod Neocalanus plumchrus in the laboratory and in the subarctic Pacific ocean. Limnol Oceanogr 32:178-188

Dam HG, Peterson WT (1988) The effect of temperature on the gut clearance rate constant of planktonic copepods. J Exp Mar Biol Ecol 123:1-14

Dam HG, Roman MR, Youngbluth MJ (1995) Downward export of respiratory carbon and dissolved inorganic nitrogen by diel-migrant zooplankton at the JGOFS Bermuda time-series station. Deep-Sea Res I 42:1187-1197

Deason EE (1980) Grazing of Acartia hudsonica (A. clausi) on Skeletonema costatum in Narragansett Bay (USA): influence of food concentration and temperature. Mar Biol 60: 101-113

Dolan JR, Coats DW (1991) A study of feeding in predacious ciliates using prey ciliates labeled with fluorescent microspheres. J Plankton Res 13(3):609-627

Durbin EG, Durbin AG (1992) Effects of temperature and food abundance on grazing and short term weight change in the marine copepod Acartia hudsonica. Limnol Oceanogr 37:361-378

Feinberg RL, Dam HG (1998) Effects of diet on dimensions, density and sinking rates of fecal pellets of the copepod Acartia tonsa. Mar Ecol Prog Ser 175:87-96

Fowler SW, Knauer GA (1986) Role of large particles in the transport of elements and organic compounds through the oceanic water column. Prog Oceanogr 16:147-194

Gamble JC (1978) Copepod grazing during a declining spring phytoplankton bloom in the Northern North Sea. Mar Biol 49:303-315

Gaudy R (1974) Feeding four species of pelagic copepods under experimental conditions. Mar Biol 25:125-141

Green EP, Harris RP, Duncan A (1992) The production and ingestion of faecal pellets by nauplii of marine calanoid copepods. J Plankton Res 14(12):1631-1643
Griffin SL (2000) Influence of food type on the production and settling rate of faecal pellets produced by an estuarine copepod. Mar Freshw Res 51(4):371-378

Guillard RRL (1975) Culture of phytoplankton for feeding invertebrates. In: Smith WL, Chanley MH (eds) Culture of marine invertebrates. Plenum Press, New York, p 29-60

Hansen B, Fotel FL, Jensen NJ, Madsen SD (1996) Bacteria associated with a marine planktonic copepod in culture. II. Degradation of fecal pellets produced on a diatom, a nanoflagellate or a dinoflagellate diet. J Plankton Res 18: 275-288

Houde SE, Roman MR (1987) Effects of food quality on the functional ingestion response of the copepod Acartia tonsa. Mar Ecol Prog Ser 86:229-238

Kiørboe T, Møhlenberg F, Nicolajsen H (1982) Ingestion rate and gut clearance in the planktonic copepod Centropages hamatus (Lilljeborg) in relation to food concentration and temperature. Ophelia 21:181-194

Kiørboe T, Møhlenberg F, Hamburger K (1985) Bioenergetics of the planktonic copepod Acartia tonsa: relation between feeding, egg production and respiration, and composition of specific dynamic action. Mar Ecol Prog Ser 26:85-97

Kiørboe T, Saiz E, Viitasalo M (1996) Prey switching behaviour in the planktonic copepod Acartia tonsa. Mar Ecol Prog Ser 143:65-75

Kleppel GS, Pieper RE, Trager GS (1988) Variability in gut content of individual Acartia tonsa from waters off southern California. Mar Biol 97:185-190

Koski M, Breteler WK, Schogt N (1998) Effect of food quality on rate of growth and development of the pelagic copepod Pseudocalanus elongatus (Copepoda, Calanoida). Mar Ecol Prog Ser 170:169-187

Landry MR, Hassett RP, Fagerness V, Downs J, Lorenzen CJ (1984) Effect of food acclimation on assimilation efficiency of Calanus pacificus. Limnol Oceanogr 29:361-364

Lee BG, Fisher NS (1994) Effects of sinking and zooplankton grazing on the release of elements from planktonic debris. Mar Ecol Prog Ser 110:271-281

Longhurst AR, Harrison WG (1988) Vertical nitrogen flux from the oceanic photic zone by diel migrant zooplankton and nekton. Deep-Sea Res 35:881-889

Morales C (1987) Carbon and nitrogen content of copepod faecal pellets: effects of food concentration and feeding behaviour. Mar Ecol Prog Ser 36:107-114

Noji TT (1991) The influence of macrozooplankton on vertical particulate flux. Sarsia 76:1-9

Paffenhöfer GA (1988) Feeding rates and behavior of zooplankton. Bull Mar Sci 43:430-445

Paffenhöfer GA, Knowles SC (1979) Ecological implications of fecal pellet size, production and consumption by copepods. J Mar Res 37:35-49

Parsons TR, Takahashi M, Hargrave B (1984) Biological oceanographic processes, 3rd edn. Pergamon Press, Oxford, p 330

Reeve MR, Walter MA (1977) Observations on the existence of lower threshold and upper critical food concentrations for the copepod Acartia tonsa Dana. J Exp Mar Biol Ecol 29:211-221

Reinfelder JR, Fisher NS (1991) The assimilation of elements ingested by marine copepods. Science 251:794-796

Rothhaupt KO (1990) Changes of the functional responses of the rotifers Brachionus rubens and Brachionus calyciflorus with particle sizes. Limnol Oceanogr 35(1):24-32

Small LF, Landry MR, Eppley RW, Carlucci AF (1989) Role of plankton in the carbon and nitrogen budgets of Santa Monica Basin, California. Mar Ecol Prog Ser 56:57-74

Sokal RR, Rohlf FJ (1981) Biometry. The principles and prac- 
tice of statistics in biological research, 2nd edn. WH Freeman and Co, New York

Støttrup JG, Jensen J (1990) Influence of algal diet on feeding and egg production of the calanoid copepod Acartia tonsa Dana. J Exp Mar Biol Ecol 141:87-105

Tang KW, Dam HG (1999) Limitation of zooplankton production: beyond stoichiometry. Oikos 84:537-542

Thor P, Cervetto G, Besiktepe S, Ribera-Maycas E, Tang KW, Dam HG (in press) Influence of two different green algal diets on specific dynamic action and incorporation of carbon into biochemical fractions in the copepod Acartia tonsa. J Plankton Res

Tsuda A, Nemoto T (1987) The effect of food concentration on the gut clearance time of Pseudocalanus minutus Kroyer (Calanoida: Copepoda). J Exp Mar Biol Ecol 107: 121-130

Tsuda A, Nemoto T (1990) The effect of food concentration on

Editorial responsibility: Kenneth Tenore (Contributing Editor), Solomons, Maryland, USA the fecal pellet size of marine copepod Pseudocalanus newmani Frost. Bull Plankton Soc Jpn 37:83-90

Urban LJ, McKenzie CH, Deibel D (1992) Seasonal differences in the content of Oikopleura vanhoeffeni and Calanus finmarchicus faecal pellets: illustrations of zooplankton food web shifts in coastal Newfoundland waters. Mar Ecol Prog Ser 84:255-264

Urban-Rich J, Hansell DA, Roman MR (1998) Analysis of copepod fecal pellet carbon using a high temperature combustion method. Mar Ecol Prog Ser 171:199-208

Vanderploeg HA (1990) Feeding mechanisms and particle selection in suspension feeding-zooplankton. In: Wotton RS (ed) The biology of particles in aquatic systems. CRC Press, Boca Raton, p 183-211

Voss M (1991) Content of copepod fecal pellets in relation to food supply in Kiel Bight and its effect on sedimentation rate. Mar Ecol Prog Ser 75:217-225

Submitted: August 4, 2000; Accepted: July 27, 2001

Proofs received from author(s): February 26, 2002 